\title{
Use of physiological and biochemical indicators to identify apple varieties resistant to drought
}

\author{
Galina Kiseleva*, Natalia Nenko, Alla Karavaeva, and Tatiana Shalyakho \\ Federal State Budget Scientific Institution «North Caucasian Federal Scientific Center of \\ Horticulture, Viticulture, Wine-making», 39 str. 40 Let Pobedy, Krasnodar, 350901, Russia
}

\begin{abstract}
As a result of global climate change in the arid regions of the world, a decrease in the adaptability of fruit crops to drought has been noted. This explains the interest of researchers in the issues of increasing the drought resistance of fruit crops in various ways, one of which is the creation of resistant varieties as a result of selection. The use of physiological and biochemical parameters in the breeding process as diagnostic criteria for drought resistance and the identification of highly adaptive varieties of fruit crops is relevant all over the world. The objects of study are apple varieties of various ecological and geographical origins: Idared, Erli Mac, Dayton (USA), Prikubanskoe, Rassvet, Fortuna (Russia). Physiological parameters: the relative water content, the total content of chlorophylls $(a+b)$, carotenoids, ascorbic acid in the leaves of the studied apple varieties were determined during periods before drought and during drought. Differences in the response of varieties to the impact of drought were revealed. It was found that apple varieties of local selection Prikubanskoye, Fortuna and American variety Idared have a greater ability to adapt to changing environmental conditions in comparison with other studied varieties. The revealed adaptive features during drought (retention of a high relative water content, stability of the pigment system, a low ratio of the total chlorophyll to carotenoids, an increased content of ascorbic acid) make it possible to use them in breeding as donors of drought resistance traits. The data of physiological and biochemical studies, obtained in the unique natural and climatic conditions of the North Caucasus region of Russia, complement fundamental research on the physiological foundations of apple tree adaptation to drought.
\end{abstract}

\section{Introduction}

In the arid regions of the world, issues of increasing the drought resistance of cultivated plants are important. The North-Caucasus region of the Russian Federation, undoubtedly, can be attributed to an arid territory, where both atmospheric and soil droughts are noted against the background of high air temperatures. As a result of recent climatic changes, a decrease in the adaptability of some apple varieties to cultivation conditions has been noted. This explains the interest of researchers in the creation of apple varieties with a wide rate of response to changing weather and climatic conditions, including summer drought.

\footnotetext{
*Corresponding author: galina-kiseleva-1960@mail.ru
} 
In modern conditions, molecular genetic methods are widely used in world breeding practice. Significant advances have been made in the study of the apple tree genome, in the detection of genes whose expression increased under drought conditions, and the localization of loci that regulate the network of genes that are activated under water stress [1-4]. All these achievements are important for use in marker-mediated breeding to increase the efficiency of the breeding process for drought tolerance of apple trees. Despite the progress achieved with the help of molecular genetic methods for conducting the genetic selection process, physiological and biochemical studies remain relevant. The use of physiological and biochemical parameters as diagnostic criteria for drought resistance and identification of highly adaptive apple varieties [5], as well as other fruit crops [6-9] is widely practiced throughout the world.

Water balance parameters, the state of the pigment complex, anatomical and morphological parameters of the leaf blade are important indicators of the physiological state of the leaf. Drought-resistant apple varieties and rootstocks have a higher water potential due to water retention by osmotically active substances, as well as the use of other mechanisms $[10,11]$. There is evidence that the chlorophyll content in the leaves of the apple cultivar resistant to drought remained stable during the period of water stress in comparison with the unstable cultivar [12]. It has been shown that the high drought resistance of the apple tree may be due to the anatomical and morphological characteristics of the leaf, which contributes to the maintenance of its higher photosynthetic activity [13].

To date, many facts have been obtained that indicate that adaptation of plants to stressful conditions correlates with an increase in antioxidant defense, the components of which are proline, peroxidase, carotenoids, ascorbic acid, etc. These metabolites can serve as markers of the development of oxidative stress and diagnostic criteria for drought resistance [14 sixteen]. The use of physiological and biochemical parameters makes it possible to single out resistant varieties as donors of selectively significant traits, which are necessary to fulfill the tasks of creating drought-resistant apple varieties.

The purpose of this work was to conduct a physiological and biochemical assessment of apple varieties of various ecological and geographical origin under the influence of drought, to identify varieties with high adaptive abilities to drought in the southern region of the Russian Federation.

\section{Materials and Methods}

The study of these varieties of apple was carried out in 2017-2019 in the pilot production farm "Central". The objects of research are diploid apple varieties of various ecological and geographical origins: Idared, Erli Mac, Dayton (USA), Prikubanskoe, Rassvet, Fortuna (Russia). Varieties Idared, Prikubanskoe - 2010 planting on SK4 rootstock with a planting pattern of 0.9 x 4.5; varieties Rassvet, Fortuna - 2000 planting on stock M 9 ( 2 × 5); varieties Erli Mac, Dayton - 1998 planting on M9 rootstock $(2 \times 5)$. For the study, fully developed leaves were selected from five trees of each variety in triplicate. Each replicate consisted of five leaves. The relative water content in the leaves was determined by the method used by $\mathrm{Li}$ [17] by drying the weighed portions of the leaves in a drying cabinet at a temperature of $105^{\circ} \mathrm{C}$ to constant weight. The experiments were carried out in triplicate. The pigment content was determined in $80 \%$ acetone extract by the spectrophotometric method using a Unico 2800 spectrophotometer (United Products \& Instruments, USA) according to the method used by Afonso [18]. The parameters of the ascorbic acid content were determined spectrophotometrically using $5 \%$ trichloroacetic acid according to the method proposed by Skłodowska [14].

The meteorological conditions during the years of research were close to those typical for the North Caucasus region of Russia. The average monthly air temperatures were $4.7^{\circ} \mathrm{C}$ 
higher than the long-term average values, the maximum air temperature rose to $+39.5{ }^{\circ} \mathrm{C}$. The average monthly amount of precipitation was $11.0-130.0 \mathrm{~mm}$. August 2018 and the third decade of August 2019 were especially dry (no precipitation). Summarizing the data of meteorological studies for 2017-2019, the physiological parameters of the studied apple varieties were determined in the periods before the impact of drought and during drought.

\section{Results and Discussion}

Insufficient water supply causes physiological disturbances in the growth and photosynthesis of the apple tree. During the period of drought, against the background of elevated temperatures, overheating of plants occurs, which increases the stress effect. In these climatic conditions, drought usually occurs in August.

The studies carried out have shown that during dry periods, all studied apple varieties had a decrease in the relative water content in leaf tissues to varying degrees. During drought, the Dayton cultivar showed a significant decrease in the relative water content by $6-8 \%$ in comparison with periods of sufficient moisture supply. For Idared and Fortuna varieties, it decreased by $2 \%$ and $3.1 \%$, respectively. In the Prikubanskoye variety, the relative water content of leaf tissues remained almost unchanged. During dry periods, the relative water content, which characterizes the water content of leaf tissues, was higher in apple varieties of domestic selection and variety Idared, indicating their increased adaptive capacity in drought conditions.

Plant resistance to drought is closely related to the state of photosynthetic pigments: chlorophyll and carotenoids. The absence of atmospheric precipitation during dry periods was not uniformly reflected in the photosynthetic activity of the studied apple varieties. Thus, the varieties Prikubanskoe and Fortuna showed a stable content of the total chlorophylls $(\mathrm{a}+$ b) during dry periods. This confirms the active adaptation of the leaf apparatus of these varieties to drought against the background of elevated temperatures. The varieties Erli Mac, Dayton showed a significant decrease in the amount of chlorophylls during dry periods. If before the impact of drought it left 6.61 and $7.53 \mathrm{mg} / \mathrm{g}$ of dry weight, respectively, then during drought it decreased to 3.87 and $4.92 \mathrm{mg} / \mathrm{g}$ of dry weight. In the rest of the studied cultivars, changes in the total chlorophyll content were not so significant (Fig. 1).

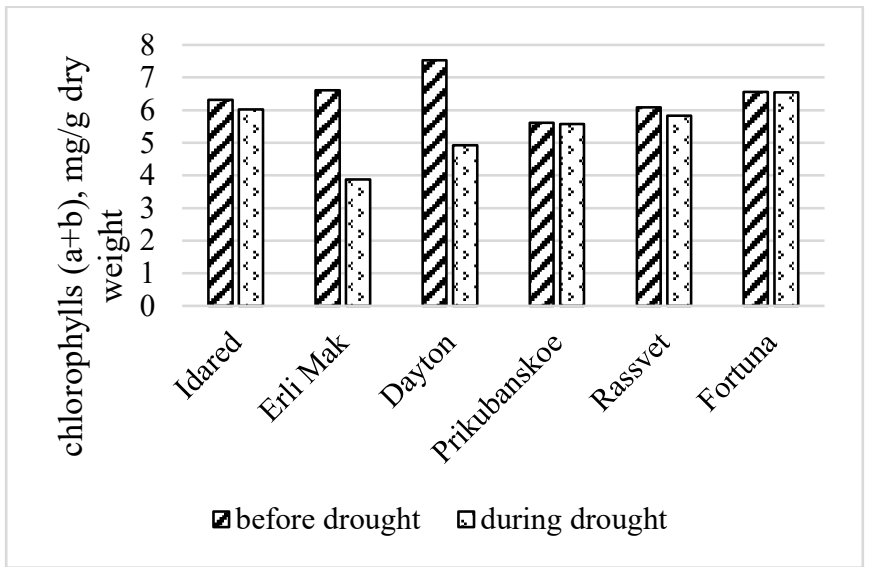

Fig. 1. Quantitative indicators of chlorophyll content in apple leaves before and during drought exposure.

An increase in the content of other pigments of photosynthesis, carotenoids, against the background of unchanged chlorophyll content indicates the activation of their protective 
function in response to stress [19]. In this regard, a more informative indicator of the state of the pigment complex is the quantitative ratio of the sum of chlorophylls to carotenoids. In our studies during periods of drought in the Prikubanskoe and Fortuna varieties, the ratio of the total chlorophylls to carotenoids was lower than in other studied varieties - 2.01-2.03, indicating an increase in the proportion of carotenoids in their pigment complex. This indicator was the highest in the varieties Erli Mac and Dayton - 2.40-3.15 (Fig. 2).

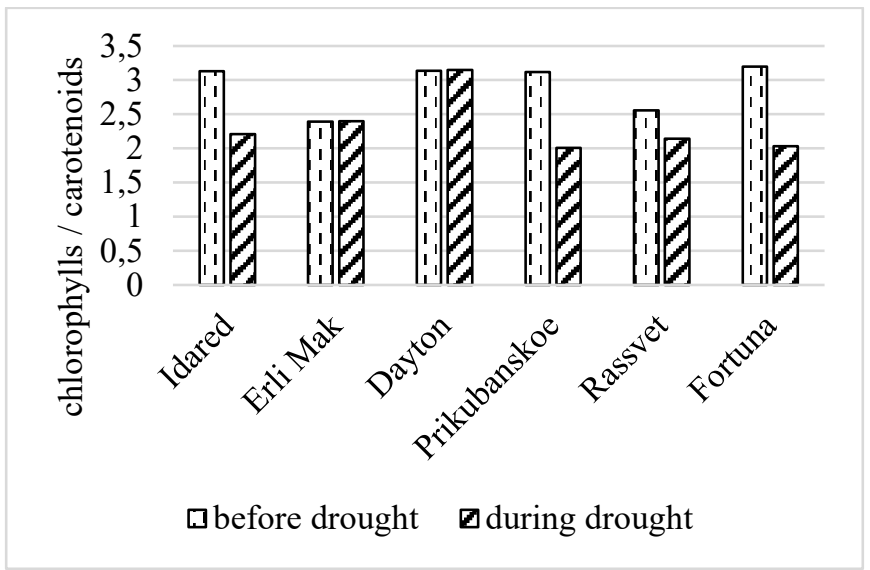

Fig. 2. The ratio of the sum of chlorophylls to carotenoids in apple leaves before and during drought.

The stress response to drought is accompanied by the production of reactive oxygen species, the detoxification of which occurs by the antioxidant defense system, an important link of which is ascorbic acid. Thus, before the drought exposure, the content of ascorbic acid in the leaves of all studied varieties varied from 3.92 to $7.15 \mu \mathrm{mol} / \mathrm{g}$ fr wt (Fig. 3).

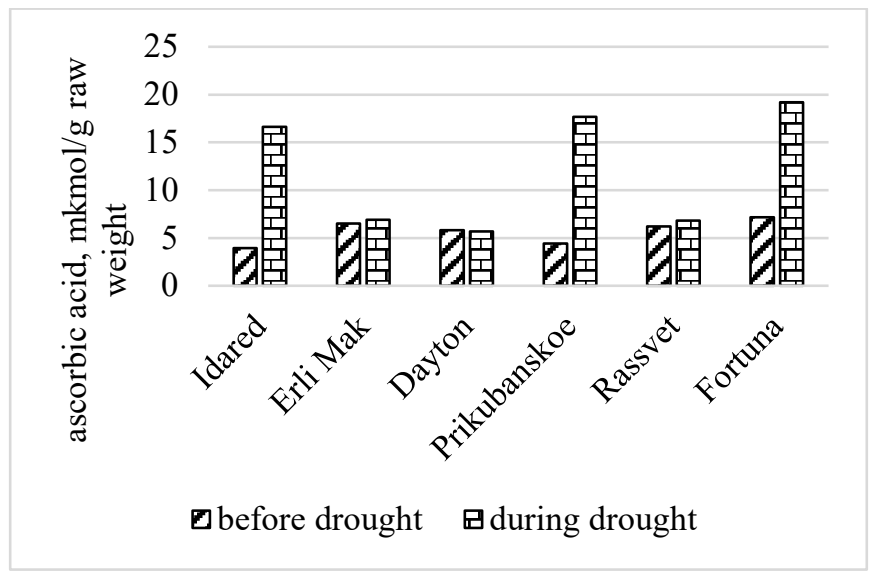

Fig. 3. Quantitative parameters of ascorbic acid content in apple leaves before and during drought exposure.

During dry periods, the varieties Prikubanskoe, Fortuna, Idared showed an increase in the content of ascorbic acid - 16.63-19.21 $\mu \mathrm{mol} / \mathrm{g}$ fr wt. In other studied varieties, the content of ascorbic acid remained almost unchanged. An increase in the content of ascorbic acid in the varieties Prikubanskoe, Fortuna, Idared indicates an increased induction of a protective response during the development of oxidative stress. 


\section{Conclusion}

The physiological and biochemical indicators used provide a reliable and reliable assessment of the drought resistance of the apple tree and can be used as diagnostic criteria. Apple varieties of local selection Prikubanskoye, Fortuna and Idared of American selection have a greater ability to adapt to changing environmental conditions in comparison with other studied varieties. The revealed adaptive features during drought (retention of a high relative water content, stability of the pigment system, a low ratio of the total chlorophyll to carotenoids, an increased content of ascorbic acid) make it possible to use them in the breeding process as sources of signs of drought resistance. Physiological and biochemical data obtained in the weather and climatic conditions of the North Caucasian region of Russia supplement fundamental research on the physiological foundations of apple tree adaptation to drought.

\section{References}

1. C. Li, C. K.-Y. Ng, L.-M. Fan, Environ. Exp. Bot., 114, 80-91 (2015) https://doi.org/10.1016/j.envexpbot.2014.06.014

2. X.-L. Li, J.-K. Zhang, M.-J. Li, B.-B. Zhou, Q. Zhang, Q.-P. Wei, J. Hortic. Sci. Biotechnol., 93(4), 337-346 (2018) https://doi.org/10.1080/14620316.2017.1382314

3. T. L. Guo, N. Wang, Y. C. Xue, Q. M. Guan, S. van Nocker, C. H. Liu, F. W. Ma, Plant Sci., 280, 397-407 (2019) https://doi.org/10.1016/j.plantsci.2018.11.018

4. X. Sun, P. Wang, X. Jia, L. Q. Huo, R. M. Che, F. W. Ma, Plant Biotechnol. J., 16 (2), 545-557 (2018) https://doi.org/10.1111/pbi.12794

5. J. González-Talice, J. A. Yuri, V. Lepe, J. Hirzel, A. del Pozo, Sci. Hortic., 146, 131-136 (2012) https://doi.org/10.1016/j.scienta.2012.07.034

6. A. Yadollahi, K. Arzani, A. Ebadi, M. Wirthensohn, S. Karimi, Sci. Hortic., 129(3), 403413 (2011) https://doi.org/10.1016/j.scienta.2011.04.007

7. S. Camposeo, M. Palasciano, G. A. Vivaldi, A. Godini, Sci. Hortic., 12(3), 234-241 (2011) https://doi.org/10.1016/j.scienta.2010.09.022

8. R. Rivas, M. T. Oliveira, M. G. Santos, Plant Physiol. Biochem., 63, 200-208 (2013) http://dx.doi.org/10.1016/j.plaphy.2012.11.026

9. I. Serra, A. Strever, P. A. Myburgh, A. Deloire, Aust. J. Grape Wine Res., 20(1), 1-14 (2014) https://doi.org/10.1111/ajgw.12054

10. T. Tworkoski, G. Fazio, D. M. Glenn, Sci. Hortic., 204, 70-78 (2016) https://doi.org/10.1016/j.scienta.2016.01.047

11. C. L. Bassett, D. M. Glenn, P. L. Forsline, M. E. Wisniewski, R. E. Ferrell Jr, HortScience, 46(8), 1079-1084 (2011) http://doi.org/10.21273/HORTSCI.46.8.1079

12. N. Bhusal, S.-G. Han, T.-M. Yoon, Sci. Hortic., 246, 535-543 (2019) https://doi.org/10.1016/j.scienta.2018.11.021

13. T. Bai, Z. Li, C. Song, S. Song, J. Jiao, Y. Liu, Z. Dong, X. Zheng, Am. J. Plant Sci., 10(5), 709-722 (2019) http://doi.org/10.4236/ajps.2019.105051

14. M. Skłodowska, E. Gajewska, E. Kuźniak, A. Mikiciński, P. Sobiczewski, Sci. Hortic., 125(1), 34-40 (2010) https://doi.org/10.1016/j.scienta.2010.02.019

15. S. Wang, D. Liang, C. Li, Y. Hao, F. Ma, H. Shu, Plant Physiol. Biochem., 51, 81-89 (2012) https://doi.org/10.1016/j.plaphy.2011.10.014

16. S. Wu, D. Liang, F. Ma, Plant Physiol. Biochem., 80, 249-258 (2014). https://doi.org/10.1016/j.plaphy.2014.04.012

17. Z. Li, M. Wang, Y. Yang, S. Zhao, Y. Zhang, X. Wang, Arid Land Research Manage., 31(4), 388-403 (2017) http://doi.org/10.1080/15324982.2017.1344332 
18. S. Afonso, C. Ribeiro, E. Bacelar, H. Ferreira, I. Oliveira, A. P. Silva, B. Gonçalves, Sci. Hortic., 225, 394-398 (2017) https://doi.org/10.1016/j.scienta.2017.07.037

19. F. Xiao, Z. Q. Yang, K. W. Lee, J. Hortic. Sci. Biotechnol., 92(1), 2-10 (2017) http://doi.org/10.1080/14620316.2016.1211493 